\title{
Effectiveness of person-centered care on people with dementia: a systematic review and meta-analysis
}

\section{Sun Kyung Kim \\ Myonghwa Park}

Education and Research Center for Evidence Based Nursing Knowledge, College of Nursing, Chungnam National University, Daejeon, Republic of Korea
Correspondence: Myonghwa Park Education and Research Center for Evidence Based Nursing Knowledge, College of Nursing, Chungnam National University, 266 Munhwa-ro, Jung-gu, Daejeon 35015, Republic of Korea Tel +82 425808328

Email mhpark@cnu.ac.kr
This article was published in the following Dove Press journal:

Clinical Interventions in Aging

17 February 2017

Number of times this article has been viewed

Background: Person-centered care is a holistic and integrative approach designed to maintain well-being and quality of life for people with dementia, and it includes the elements of care, the individual, the carers, and the family.

Aim: A systematic literature review and meta-analysis were undertaken to investigate the effectiveness of person-centered care for people with dementia.

Methods: Literature searches were undertaken using six databases including Medline, EMBASE, CINAHL, PsycINFO, Cochrane Database, and KoreaMed using the following keywords: cognition disorder, dementia, person-centered care, patient-centered care, clientcentered care, relationship-centered care, and dementia care. The searches were limited to interventional studies written in English and Korean and included randomized controlled studies and noncontrolled studies for people with dementia living in any setting.

Results: Nineteen interventional studies, including 3,985 participants, were identified. Of these, 17 studies were from long-term care facilities and two studies were from homecare settings. The pooled data from randomized controlled studies favored person-centered care in reducing agitation, neuropsychiatric symptoms, and depression and improving the quality of life. Subgroup analysis identified greater effectiveness of person-centered care when implemented for people with less severe dementia. For agitation, short-term interventions had a greater effect (standardized mean difference [SMD]: $-0.434 ; 95 \%$ conference interval [CI]: -0.701 to -0.166 ) than long-term interventions (SMD: -0.098 ; $95 \% \mathrm{CI}:-0.190$ to 0.007 ). Individualized activities resulted in a significantly greater beneficial effect than standard care (SMD: 0.513 ; $95 \%$ CI: -0.994 to -0.032 ). However, long-term, staff education, and cultural change interventions had a greater effect on improving the quality of life for people with dementia (SMD: 0.191 ; 95\% CI: 0.079 to 0.302 ).

Conclusion: This systematic review and meta-analysis provided evidence for personcentered care in clinical practice for people with dementia. Person-centered care interventions were shown to reduce agitation, neuropsychiatric symptoms, and depression and to improve the quality of life. Person-centered care interventions can effectively reduce agitation for a short term using intensive and activity-based intervention. However, an educational strategy that promotes learning and skill development of internal care staff is needed to enhance patient's quality of life and to ensure the sustainability of the effects of behavioral problems. The feasibility and effectiveness of the intervention, the severity of patient disease, and intervention type and duration should be considered as part of an intervention design.

Keywords: dementia, meta-analysis, patient-centered care, person-centered care, neuropsychiatric symptoms, systematic review 


\section{Introduction}

Dementia affects 46.8 million people worldwide and this number is expected to increase rapidly to 131.5 million by $2050 .{ }^{1}$ Neuropsychiatric symptoms (NPS) are of primary concern for dementia care as they are difficult to manage and lead to patients being institutionalized. Health care provider may use psychotropic drugs to treat or control NPS, although psychotropic drugs are recognized to have harmful side effects. Nonpharmacological interventions may be a more beneficial treatment for people with dementia. ${ }^{2}$

Person-centered care (PCC), also known as patientcentered care, is a sociopsychological treatment approach that recognizes the individuality of the patient in relation to the attitudes and care practices that surround them. ${ }^{3}$ The PCC approach recognizes that there are unmet needs, such as isolation, that may be the basis of behavioral symptoms or NPS in patients with dementia. ${ }^{4}$ The PCC approach enables health care providers to understand and provide support for the unmet needs of the individual with dementia. ${ }^{5}$

PCC for people with dementia has been widely developed and implemented mainly in long-term care facilities. In clinical practice, PCC includes incorporating personal knowledge of the person with dementia, conducting meaningful activities, making well-being a priority, and improving the quality of the relationships between the health care provider and the individual with dementia. ${ }^{6,7}$ There have been several recent developments in PCC. Dementia care mapping $(\mathrm{DCM})^{8}$ and treatment routes for exploring agitation (TREA) ${ }^{9}$ are examples of PCC for individuals with dementia. DCM as a method of implementing PCC for people with dementia designs care planning based on systematic observation of factors associated with behavioral problems. Also, continuous training and feedback enable care staff to develop further PCC skills in daily practice. ${ }^{9}$ The TREA uses systematic algorithms to suggest best possible interventions to address dementia-compromised behaviors through data collection and observation of people with dementia. ${ }^{9}$

Large-scale staff education interventions ${ }^{10}$ using the VIPS (V, the value of human life; I, an individualized evaluation of individuality; $\mathrm{P}$, an understanding of patient perspective; S, positive social psychology to improve relative well-being) practice model (VPM) and DCM in nursing home settings showed lasting effectiveness in reducing the level of depression and improving the quality of life (QoL) after a 10-month period. However, these interventions did not show effectiveness in controlling patient agitation. Other strategies, including TREA ${ }^{9}$ and therapeutic recreation programs, ${ }^{11}$ that have been employed to decrease agitation included tailored activities that were prescribed after the thorough examination of unique characteristics, strength, and weakness of individuals. In these strategies, the research team and therapists worked directly with individuals with dementia residing in long-term care facilities or their home and showed a reduction in agitation between 10 and 14 days following completion of the interventions. ${ }^{9,11}$ Focusing on behavioral issues, these studies did not provide evidence for effectiveness on psychological outcomes, such as depression or QoL., ${ }^{9,11}$

There have been some recent government guidelines and dementia plans emphasizing the importance of a personcentered approach. ${ }^{3-5,12-14}$ Recently published reviews of PCC interventions for individuals with dementia have shown beneficial effects for managing challenging behaviors, reducing the use of antipsychotic drugs, and improving job satisfaction in staff. ${ }^{8,15-17}$ However, there were several limitations associated with these previous reviews, as they provided insufficient evidence to guide the practical use of PCC in dementia care. Instead of focusing on the effectiveness of PCC for dementia, authors used narratives to report the application of PCC for older adults in general ${ }^{8,15}$ or care staff. ${ }^{16} \mathrm{~A}$ review with a quantitative synthesis ${ }^{17}$ included four studies that published all materials, including their manuals, but they excluded many other interventions that were not included in their manuals.

There remains a need to evaluate the effectiveness of PCC in individuals with dementia because this devastating and increasingly common condition impacts all aspects of physical and psychological function and requires significant caregiving support. ${ }^{18}$ The people with dementia express symptoms in individualized ways that could be triggered by several factors. The person-centered approach may provide the best interpretation for why such symptoms appear, as all disease-related symptoms and limitations threaten normality and maintenance of human dignity, for individuals with dementia. ${ }^{18}$ When the disease has progressed to a point where individuals with dementia need significant assistance and support, they may be no longer have the ability to express their care needs as they may not be able to articulate or possess insight regarding care availability. Therefore, the purpose of this systematic review and meta-analysis was to synthesize the current evidence of the effects of personcentered interventions for individuals with dementia and patient outcome. Therefore, a systematic literature review and meta-analysis were undertaken to investigate the effectiveness of PCC for people with dementia.

\section{Methods}

\section{Meta-analysis}

Meta-analysis of the data obtained from the systematic literature review on PCC was conducted according to the 
guidelines of the Preferred Reporting Items for Systematic Reviews and Meta-analysis. ${ }^{19}$

\section{Inclusion criteria}

Criteria for the inclusion of published studies in this review were based on the PICOT (Population/Patient Problem, Intervention, Comparison, Outcome and Time) format of study design questions. Studies were included if they met these following criteria:

1. Studies that included participants ( $>70 \%)$ from any setting who had dementia diagnosed by health professionals, regardless of dementia type and severity.

2. Interventional studies that compared PCC with "usual care" that used the core components of PCC. ${ }^{7}$ Studies that used a) the following terminology: PCC, patient-centered care, client-centered care, or DCM or b) highlighted the preferences and needs of the individuals studied.

3. Studies that reported at least one primary patient outcome of agitation or NPS. Secondary outcomes included quantitative measurement of QoL or level of depression (self-reported or reported by questionnaire).

4. The well-being of individuals with dementia determined by reduced NPS, mood control, and improved QoL.

These four outcomes were chosen because of their strong association with dementia and because a pilot search of the literature identified these as the most frequently reported and best-studied areas in personcentered dementia care.

5. Studies designed as clinical randomized controlled trials (RCTs) and non-RCTs that explored the effectiveness of PCC interventions.

\section{Search strategy}

In terms of time period, the search did not restrict the publication date as we aimed to maximize the number of potential studies included. Six databases were searched from April 1963 to September 2015. The databases included Medline, EMBASE, CINAHL, PsycINFO, the Cochrane Database, and KoreaMed. Of the core databases for health and social science, Medline, EMBASE, and the Cochrane library were selected. As PCC is an intervention that targets humans, especially the elderly with dementia, the databases that matched study intervention and population were chosen to include CINAHL, PsycINFO, and KoreaMed. In addition, manual searching of key reference lists from review articles was performed. The keywords used included cognition disorder (Mesh), dementia (Mesh), PCC, patient-centered care (Mesh), client-centered care, relationship-centered care, and DCM (Table S1).

\section{Selection of studies}

The eligibility screening processes were based on the Cochrane Handbook for Systematic Reviews of Interventions. ${ }^{20}$ Two independent reviewers searched the databases and reviewed the literature and then met to decide on the inclusion of the studies. Any disagreements between the reviewers were referred to a third person to achieve a consensus.

\section{Data extraction}

Two independent reviewers used a standardized data extraction method adapted from the Cochrane Collaboration model. ${ }^{20}$ The extracted data included information about samples, study methods, interventions, and outcomes.

\section{Quality assessment}

The two independent reviewers examined the risk of bias (ROB) for all included studies using two analysis tools: the Cochrane Collaboration's ROB ${ }^{21}$ for studies with randomized controlled design and the ROB assessment tool for nonrandomized studies (ROBANS) for non-RCTs. ${ }^{22}$ The publication bias was examined using funnel plots for outcome studies that included $>10$ evaluations (Figure S1) ${ }^{19}$ To examine overall quality of the evidence, the Grading of Recommendations Assessment, Development and Evaluation was used (Table S2).

\section{Data synthesis and analysis}

All data analyses and syntheses were performed using comprehensive meta-analysis software, Version 3.0. ${ }^{23}$ The standardized mean difference (SMD) was calculated with $95 \%$ conference interval $(\mathrm{CI})$, as the included studies used different measures in scoring outcomes. Additional subgroup analysis was performed to study heterogeneity between the studies using the $I^{2}$ value. The included studies were divided into four subgroups on the basis of the following:

1. The severity of dementia in the study participants was determined using the mean mini mental state examination (MMSE) score. The severe dementia group had an MMSE score $\leq 10$, and the less severe dementia group had an MMSE $>10$.

2. The intervention type: staff training or culture change vs individualized activities.

3. The duration of the intervention: short term $=10$ days3 months; long term $=>3$ months.

\section{Results}

\section{Data extraction}

Electronic searches identified a total of 18,157 records. Following screening and removal of study duplications, 
11,149 studies were identified, from which 77 studies underwent full-text review following review of the titles and abstracts.

The majority of published studies $(n=11,075)$ were excluded because they were not original studies, were not about dementia, focused on staff outcomes only, were qualitative studies or studies without a comparator group, or were secondary sources or literature reviews. The remaining 58 articles were excluded because the study designs and/or interventions were inconsistent with the required inclusion criteria or because they represented conference proceeding or protocol studies.

Following examination of the full text of selected articles, an additional eight studies were identified by manual search. Nineteen interventional studies, including 3,985 participants, were identified. Of these, 17 studies were from long-term care facilities and two studies were from homecare settings. Of the 19 interventional studies on PCC, there were 15 RCTs and four non-RCTs, of which three studies had insufficient raw data to allow for meta-analysis. ${ }^{24-26}$ Therefore, 16 studies underwent meta-analysis (Figure 1).

\section{Characteristics of the included studies}

The summary of characteristics of 19 included studies is presented in Table 1. The studies on PCC were categorized into two groups, based on the type of intervention. The first group included studies with an intervention that used individualized activities.

1. Eight individualized intervention studies: eight of 19 studies developed individualized interventions based on an understanding of preference, histories, needs, and abilities of people with dementia. The selected studies including PCC-based activities were directly interventional by trained health care staff with expertise in recreational therapy, ${ }^{11,24,25}$ psychology, ${ }^{9,27-30}$ geriatric psychiatry, ${ }^{28}$ gerontology, ${ }^{9,27}$ and social work. ${ }^{29}$ Tailored activities were prescribed for patients with behavioral or NPS and intervention periods ranged from 10 days to 30 weeks, with a mean duration of 6 weeks. None of these nine studies conducted follow-up after the intervention. Of these nine individualized interventional studies, two implemented the TREA ${ }^{9,27}$ to tackle unmet needs of individuals with dementia using a systematic algorithm.

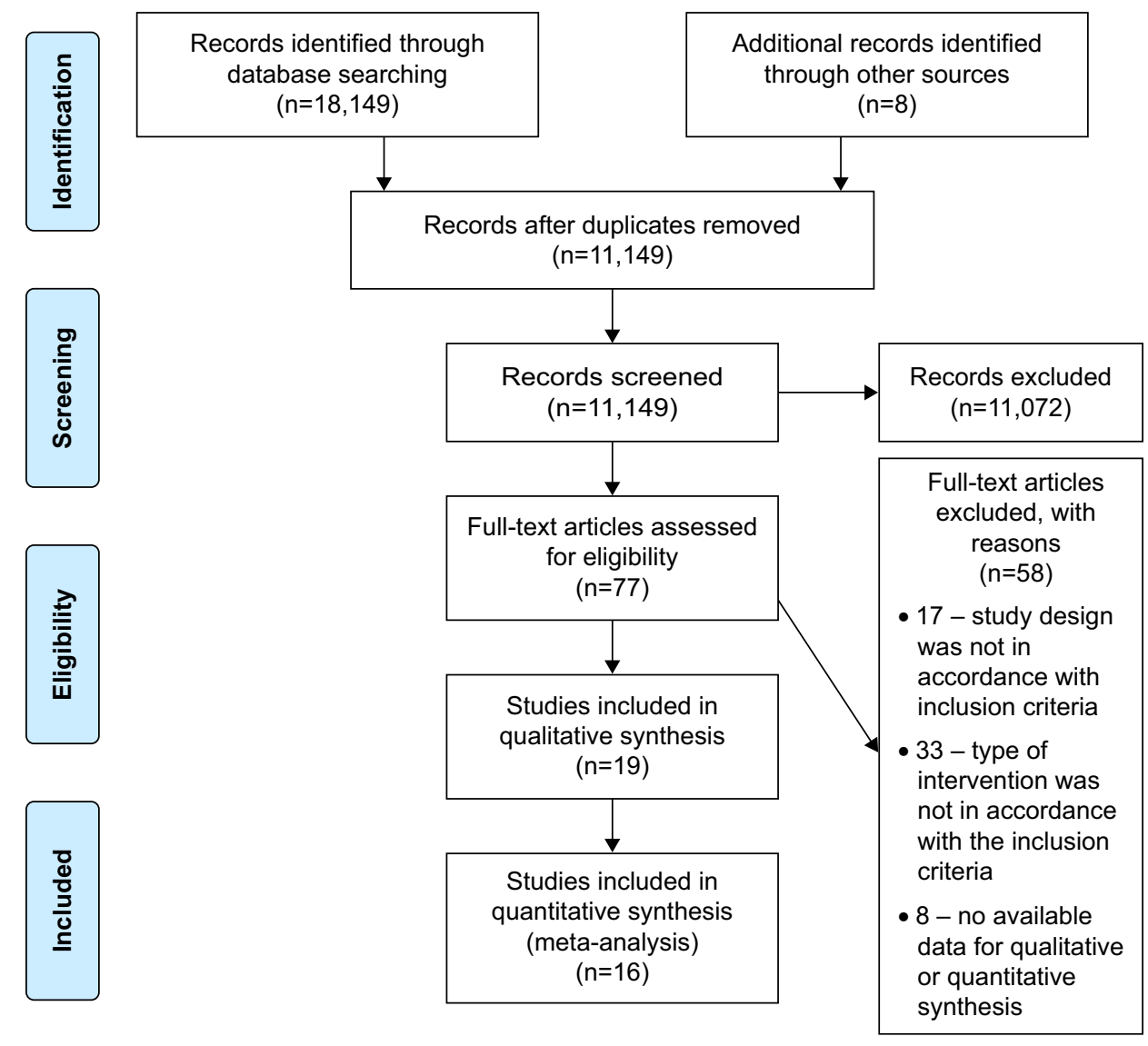

Figure I Study flow diagram.

Note: Moher D, Liberati A, Tetzlaff J, Altman DG; PRISMA Group. Preferred reporting items for systematic reviews and meta-analyses: the PRISMA statement. Ann Intern Med. 2009;15I(4):264-269, W64. Creative Commons license and disclaimer available from: http://creativecommons.org/licenses/by/4.0/legalcode"http://creativecommons. org/licenses/by/4.0/legalcode. ${ }^{19}$ 


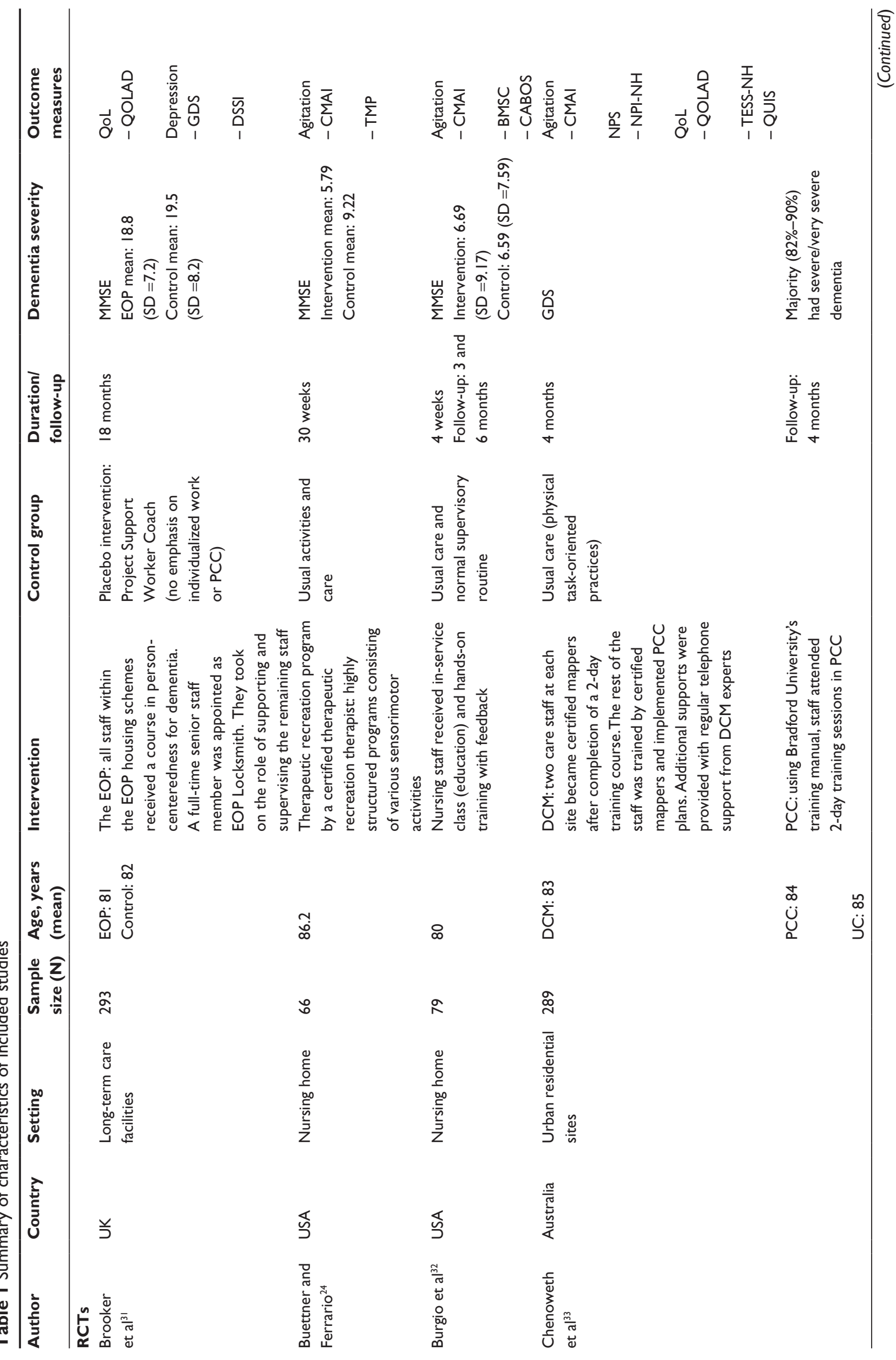




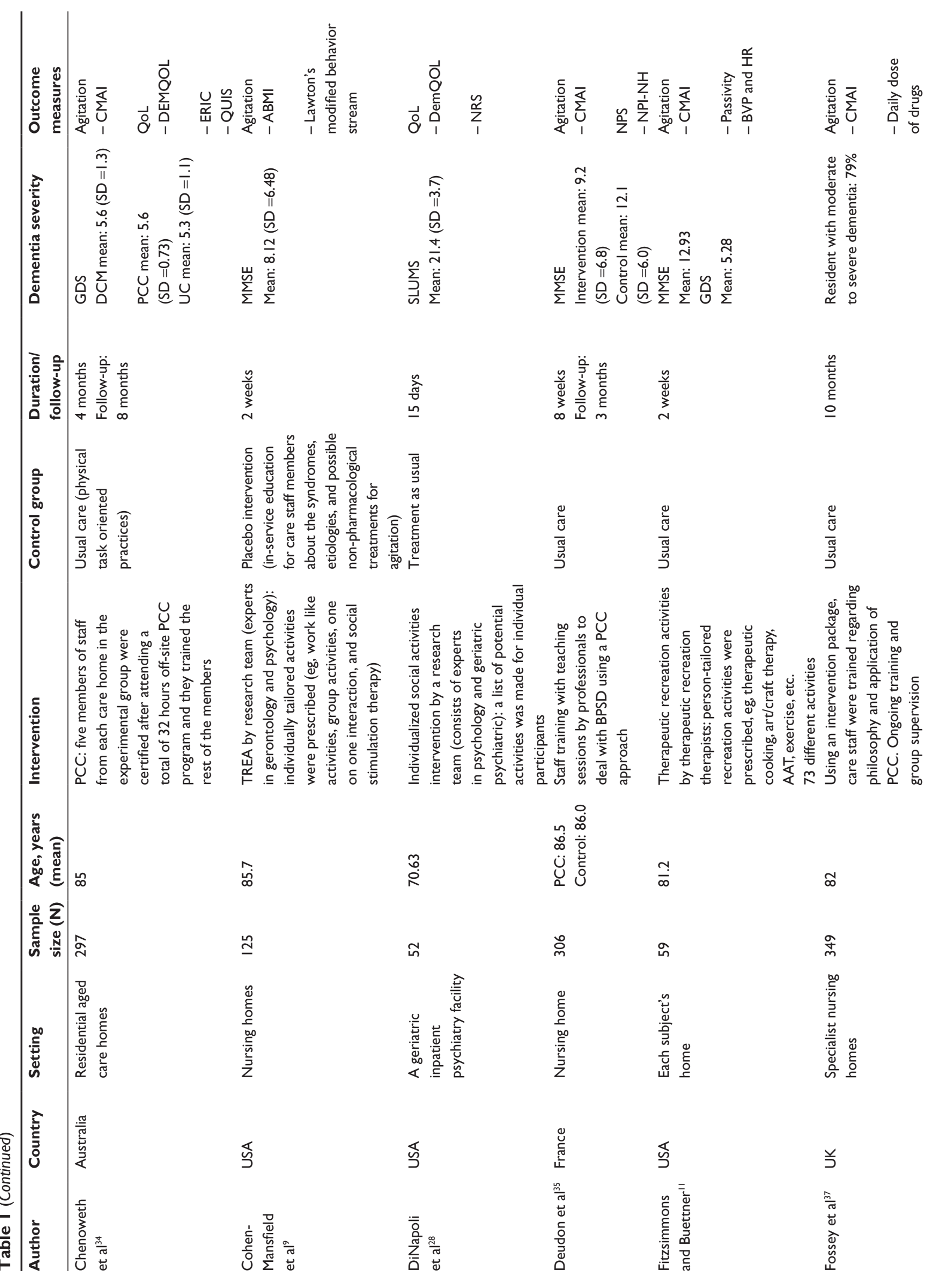




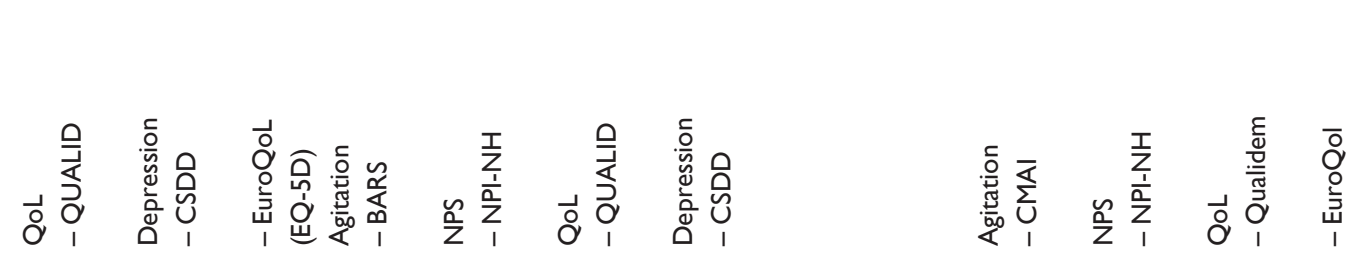

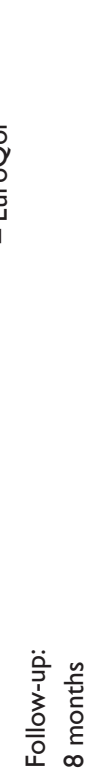

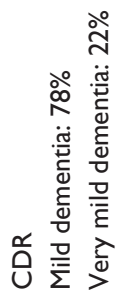

ชิ

$\stackrel{\infty}{\text { I }}$
$\ddot{\tilde{d}}$
$\stackrel{\mathbb{\infty}}{\Sigma}$

$\S$

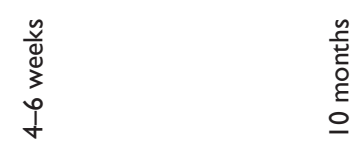

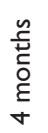

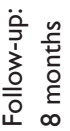
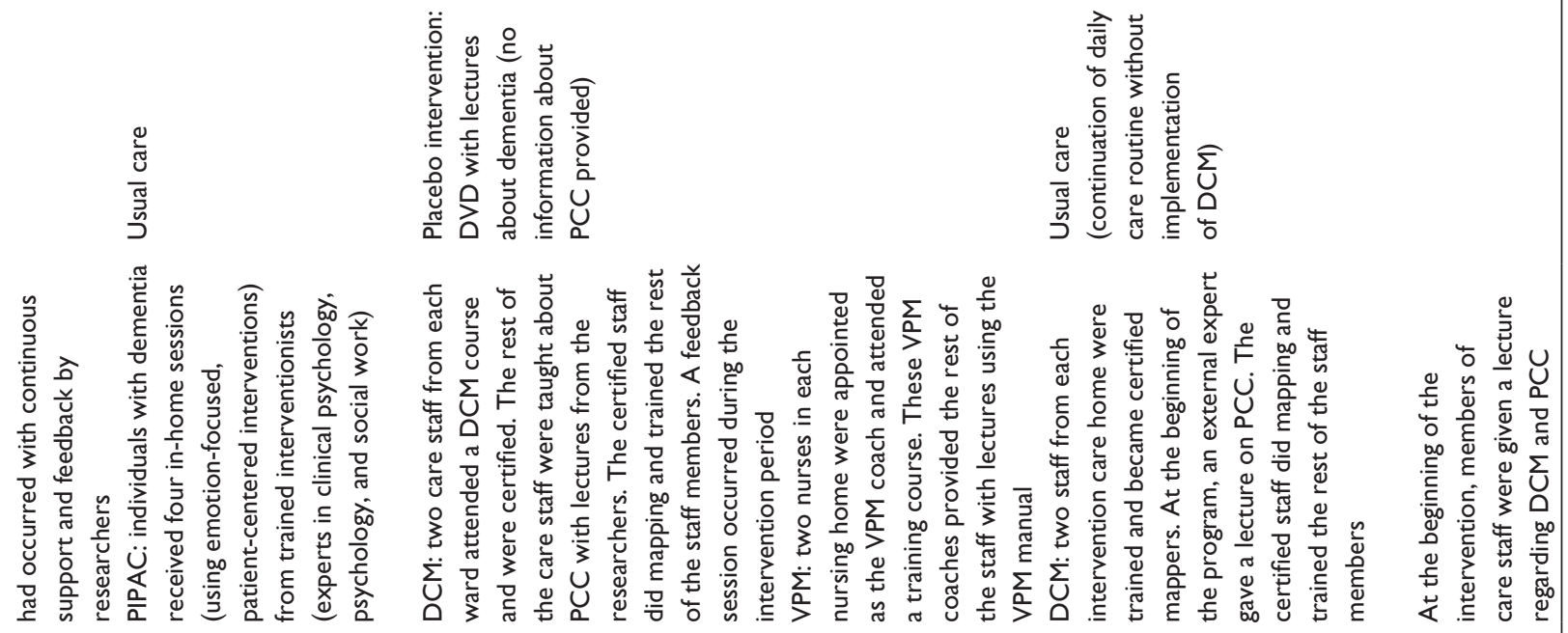

$\stackrel{\infty}{\infty}$

ڤ્仓

广户

$\underline{-}$

ปัర

$\stackrel{\infty}{\sim}$

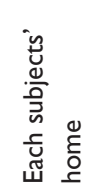

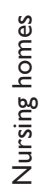

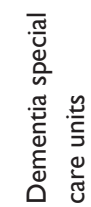

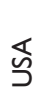

Z

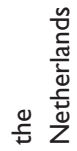

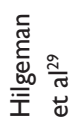

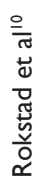

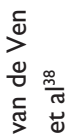




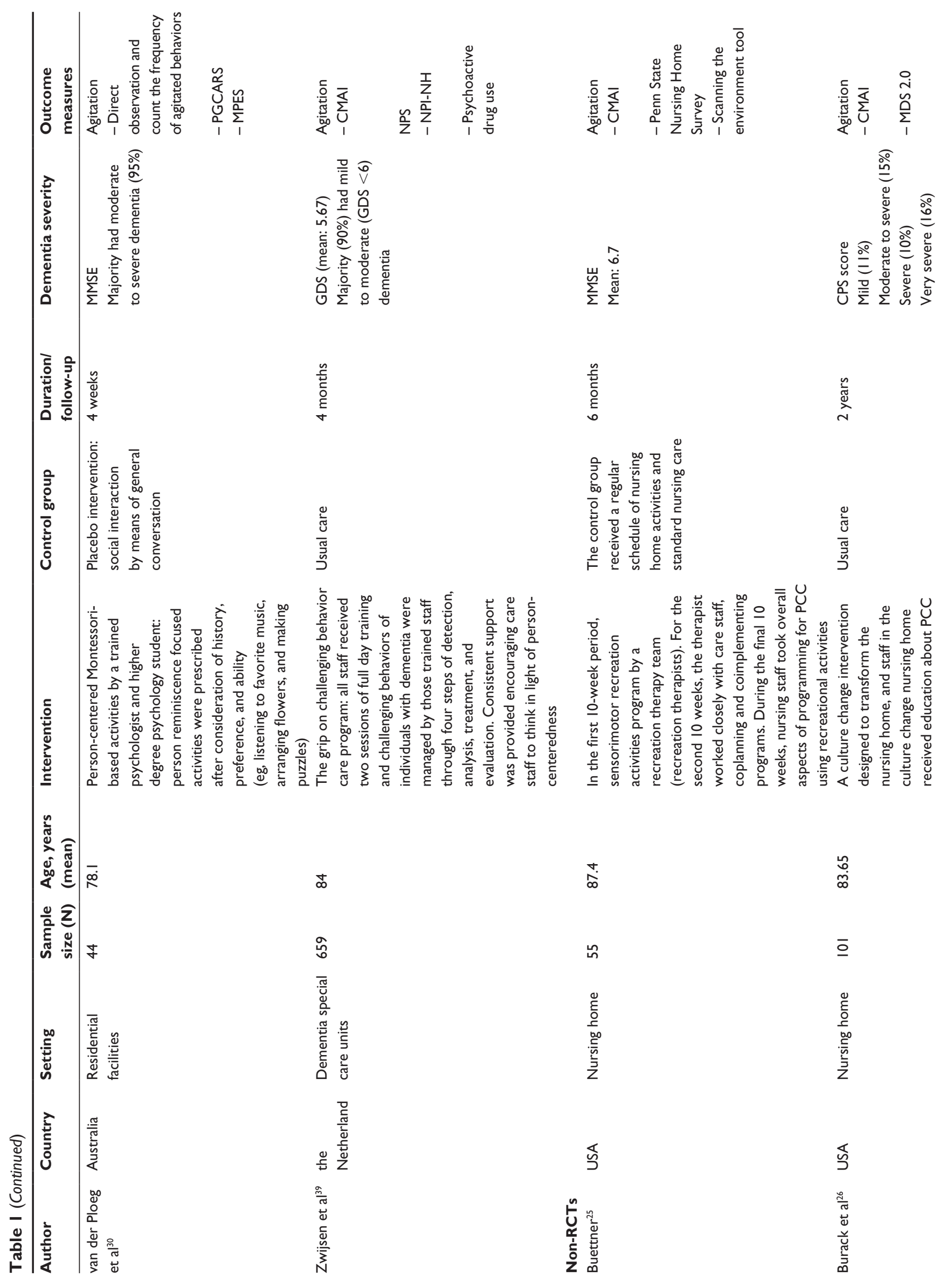




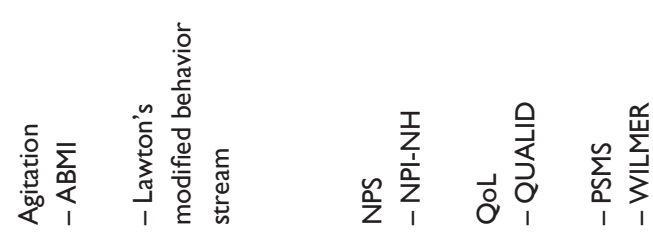
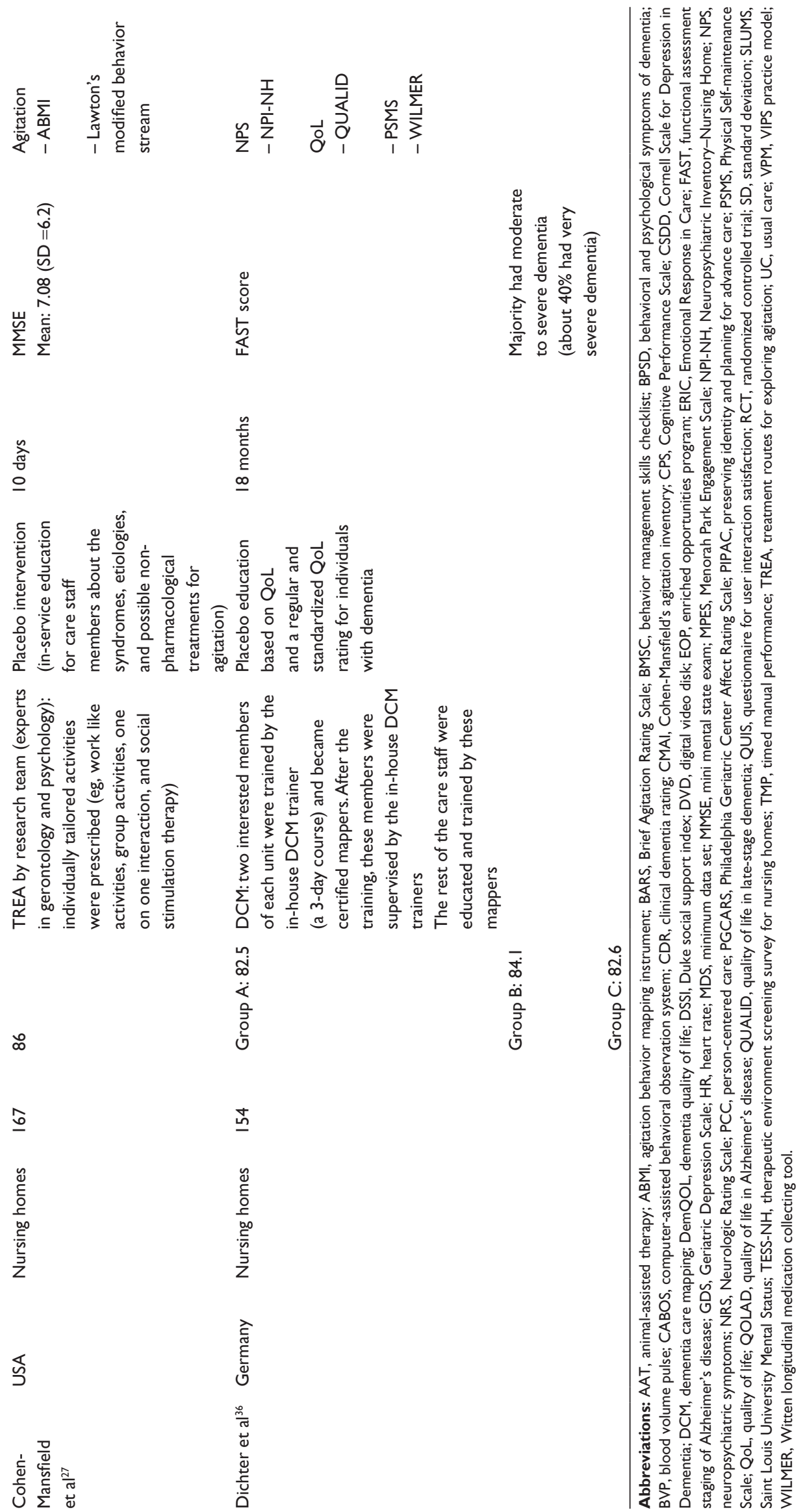

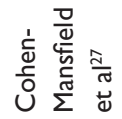

$$
\begin{aligned}
& \text { 总 }
\end{aligned}
$$

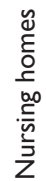

$$
\begin{aligned}
& \text { ڤ્) }
\end{aligned}
$$

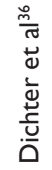

$\overline{\dot{0}}$
$\dot{0}$
0
0
$\overline{0}$
$\dot{0}$
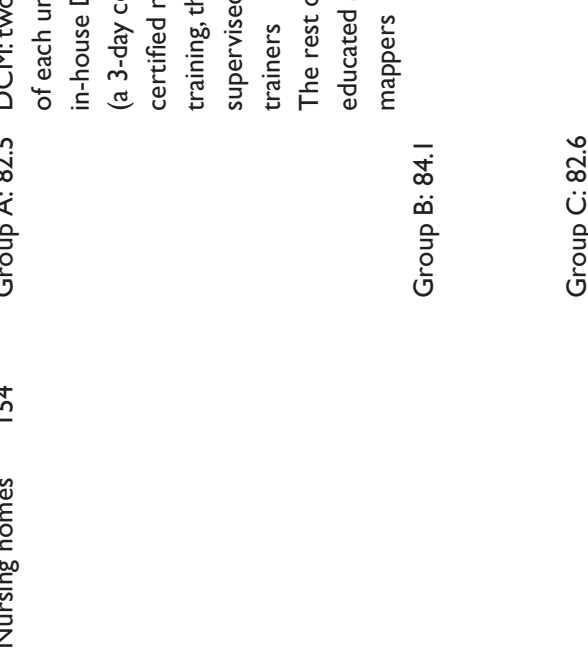

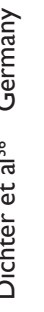


Three studies ${ }^{11,24,25}$ used therapeutic recreational activities conducted by a recreation therapist; one study ${ }^{18}$ detailed information about the staff involvement over 30-week intervention period, but details of interventions were not described in the other two studies. For example, positive emotions were developed in the study by van der Ploeg et $\mathrm{al}^{30}$ who incorporated a specific Montessori educational system with a PCC approach. Hilgeman et $\mathrm{al}^{29}$ implemented preserving identity and planning for advance care intervention that focused on personally tailored communication and interactions targeting positive emotional outcome. DiNapoli et al ${ }^{28}$ carried out individualized social activities intervention.

2. Eleven care staff-directed studies: eleven of the 19 studies $^{10,26,31-39}$ included staff education and training on empathy and person-centeredness and feedback for care staff, with long intervention duration that ranged from 3 months to 2 years. Five out of 10 studies conducted follow-up that allowed evaluation of intervention durability and outcomes. In six studies, ${ }^{10,31,33,34,36,38}$ some staff members became PCC leaders. DCM was used in four studies ${ }^{10,33,36,38}$ where two staff members from each unit became certified mappers who were in charge of care planning and staff education. In other interventions, the $\mathrm{VPM}^{10}$ and $\mathrm{PCC}^{33,34}$ were used, one in each unit was certified following completion of the off-site PCC program and provided education and training for the remaining staff. One study conducted an enriched opportunities program (EOP), ${ }^{31}$ the one senior staff member was appointed as EOP Locksmith or leader of the program. Besides providing training and education, the leaders of these interventions took a role in developing individualized care plans that included consideration of the history, preferences, and needs of the people with dementia. One study conducted an EOP. ${ }^{31}$ The other studies did not state the specific roles of the care staff. However, some details regarding education or training sessions for all staff were included in four studies. ${ }^{32,35,37,39}$ Except for one study, ${ }^{35}$ continuous support and feedback were ensured by regular meeting with researchers or external experts in intervention designs. One study ${ }^{26}$ reported that a cultural change model-based intervention was performed, consisting of staff education and organizational structure changes.

\section{Quality of the included studies}

Using the Cochrane Collaboration's $\mathrm{ROB}^{21}$ for $15 \mathrm{RCT}$ and the ROBANS for four non-RCTs, ${ }^{22}$ the overall quality of the clinical trials was low to moderate. The results of the assessment of potential bias in each study are reported in Table 2.

In most studies, there was a high risk or unclear bias assessed in allocation concealment ${ }^{10,11,24,29,30,31,36,39,40}$ and blinding of outcome assessment. ${ }^{10,11,29-31,33,36,39}$ Several studies reported the lack of blinding of study participants,, ,29,31,36,39,40 due to the nature of the interventions. Some studies were deemed to have attrition bias due to missing data. ${ }^{28,31,40}$ Although the authors acknowledged the missing data and reported the reasons, there was a substantial loss of study participants with imbalanced attrition between the groups. This attrition bias may have affected the study outcome.

\section{Effects of intervention}

\section{Agitation}

Fifteen studies examined effects of PCC on agitation using Cohen-Mansfield agitation inventory, agitation behavior mapping instrument, and Brief Agitation Rating Scale and positive effects were observed in eight studies, including two studies that were not eligible for meta-analysis. ${ }^{19,20}$ The metaanalysis on the effectiveness of PCC on agitation included 12 studies (Figure 2). On pooling data from 11 RCTs, the result favored a PCC intervention (SMD: -0.226 ; 95\% CI: -0.350 to -0.095$)$. Short-term PCC interventions had a greater effect (SMD: -0.434 ; 95\% CI: -0.701 to -0.166 ) compared with long-term interventions (SMD: $-0.098 ; 95 \%$ CI: -0.190 to 0.007 ). There was a significantly greater effect of individualized activities (SMD: $-0.513 ; 95 \%$ CI: -0.994 to -0.032 ) compared with staff training or culture change intervention (SMD: $-0.160 ; 95 \%$ CI: -0.274 to -0.046 ). Groups with smaller numbers of individuals with severe dementia had significantly improved effects (SMD: $-0.297 ; 95 \%$ CI: -0.463 to -0.132 ) while the results in the severe dementia group were not statistically significant. Five studies measured the degree of agitation following completion of the intervention, and four studies showed effects at $3,{ }^{32,35} 4,{ }^{33} 6,{ }^{32}$ and 8 months ${ }^{35}$ of follow-up.

\section{NPS}

The effects of PCC on NPS were evaluated in six studies using the Neuropsychiatric Inventory-Nursing Home (NPI-NH) and out of these, two studies found a positive effect. We extracted numerical values of NPS pooled data from six studies (Figure 3). On pooling data from five RCTs, the results indicated that PCC reduced NPS (SMD: -0.197 ; 95\% CI: -0.306 to -0.088$)$. Three studies conducted follow-up at $3,{ }^{35} 4,{ }^{33}$ and $8 .{ }^{38}$ No study showed long-term effects of PCC and NPS. 
Table 2 Assessment of risk of bias for included studies

\begin{tabular}{|c|c|c|c|c|c|c|c|}
\hline \multirow{2}{*}{$\begin{array}{l}\text { Author } \\
\text { RCTs }\end{array}$} & \multicolumn{2}{|c|}{ Selection bias } & \multirow{2}{*}{$\begin{array}{l}\text { Performance bias } \\
\text { Blinding } \\
\text { of participants } \\
\text { and personnel }\end{array}$} & \multirow{2}{*}{$\begin{array}{l}\text { Detection bias } \\
\text { Blinding } \\
\text { of outcome } \\
\text { assessment }\end{array}$} & \multirow{2}{*}{$\begin{array}{l}\text { Attrition bias } \\
\text { Incomplete } \\
\text { outcome } \\
\text { data }\end{array}$} & \multirow{2}{*}{$\begin{array}{l}\text { Reporting bias } \\
\text { Selective } \\
\text { outcome } \\
\text { reporting }\end{array}$} & \multirow{2}{*}{$\begin{array}{l}\text { Other } \\
\text { bias }\end{array}$} \\
\hline & $\begin{array}{l}\text { Sequence } \\
\text { generation }\end{array}$ & $\begin{array}{l}\text { Allocation } \\
\text { concealment }\end{array}$ & & & & & \\
\hline Brooker et $\mathrm{al}^{3 !}$ & o & 0 & $\mathrm{v}$ & $x$ & o & o & o \\
\hline Buettner and Ferrario ${ }^{24}$ & ○ & v & v & $\circ$ & ० & ० & $\circ$ \\
\hline Burgio et $\mathrm{al}^{32}$ & $\mathrm{v}$ & v & $\mathrm{v}$ & $\mathbf{v}$ & ० & $v$ & ० \\
\hline Chenoweth et $\mathrm{al}^{33}$ & ० & ० & $x$ & ० & ० & ० & ० \\
\hline Chenoweth et $\mathrm{al}^{34}$ & ○ & ० & $\mathbf{v}$ & ० & $x$ & ० & ० \\
\hline Cohen-Mansfield et al ${ }^{9}$ & $\circ$ & $\mathbf{v}$ & ० & $x$ & $\circ$ & $\circ$ & $\mathrm{v}$ \\
\hline DiNapoli et $\mathrm{al}^{28}$ & ० & ० & $v$ & ○ & $x$ & ○ & ○ \\
\hline Deudon et $\mathrm{al}^{35}$ & $\mathrm{v}$ & $\mathbf{v}$ & $x$ & v & ○ & $x$ & $v$ \\
\hline Fitzsimmons and Buettner ${ }^{\prime \prime}$ & $\mathrm{v}$ & v & v & v & ० & ○ & ० \\
\hline Fossey et $\mathrm{al}^{37}$ & ○ & $\circ$ & v & ० & ० & ○ & $\circ$ \\
\hline Hilgeman et $\mathrm{al}^{29}$ & $v$ & $v$ & $x$ & $x$ & ० & ० & ० \\
\hline Rokstad et al ${ }^{10}$ & ○ & ○ & $x$ & ○ & ○ & ○ & ० \\
\hline van de Ven et $\mathrm{al}^{38}$ & $\circ$ & $\mathbf{v}$ & $x$ & v & $\circ$ & $\circ$ & $\mathrm{v}$ \\
\hline van der Ploeg et $\mathrm{al}^{30}$ & ० & $x$ & v & $x$ & ○ & ○ & ○ \\
\hline Zwijsen et $\mathrm{al}^{39}$ & $\circ$ & v & $x$ & ० & $x$ & $\circ$ & $\circ$ \\
\hline Non-RCTs & $\begin{array}{l}\text { Selection of } \\
\text { participants }\end{array}$ & $\begin{array}{l}\text { Confounding } \\
\text { variables }\end{array}$ & $\begin{array}{l}\text { Measurement of } \\
\text { exposure }\end{array}$ & $\begin{array}{l}\text { Blinding } \\
\text { of outcome } \\
\text { assessment }\end{array}$ & $\begin{array}{l}\text { Incomplete } \\
\text { outcome } \\
\text { bias }\end{array}$ & $\begin{array}{l}\text { Selective } \\
\text { reporting }\end{array}$ & $\begin{array}{l}\text { Other } \\
\text { bias }\end{array}$ \\
\hline Buettner $^{25}$ & $x$ & v & o & v & o & o & $\circ$ \\
\hline Burack et $\mathrm{al}^{26}$ & ० & ० & ० & $x$ & $x$ & ० & ० \\
\hline Cohen-Mansfield et $\mathrm{al}^{27}$ & ० & ○ & ० & v & ० & ○ & ० \\
\hline Dichter et $\mathrm{al}^{36}$ & $x$ & ० & ० & $x$ & ० & ० & ० \\
\hline
\end{tabular}

Note: High risk of bias (x), low risk of bias (o), unclear risk of bias (v).

Abbreviation: RCT, randomized controlled trial.

QoL

Eight studies examined the effects of PCC on QoL using the QoL in late-stage dementia (QUALID), Qualidem, DemQOL, and QoL in Alzheimer disease (QOLAD) scales. A positive effect of PCC was found in four studies. We extracted numerical values of QoL from eight studies (Figure 4).

Pooling data from seven RCTs showed a positive effect of PCC on QoL (SMD: 0.199; 95\% CI: 0.090 to 0.309). Long-term interventions improved the individual QoL (SMD: 0.191 ; 95\% CI: 0.079 to 0.302), whereas shortterm interventions did not have a statistically significant impact on the QoL of dementia patients (SMD: 0.423; 95\% CI: -0.138 to 0.984 ). Groups with staff training and cultural change interventions had statistically significant effects (SMD: 0.191; 95\% CI: 0.179 to 0.302 ), whereas the results of the severe dementia group were not statistically significant. QoL had a greater effect on PCC when conducted on patient groups with smaller proportions of severe dementia (SMD: 0.278 ; 95\% CI: 0.133 to -0.422 ).

Three studies reported follow-up data, and one study ${ }^{34}$ found long-term effects on QoL 8 months later. Two studies measured QoL after the intervention but showed no effects at $4^{33}$ and 8 months $^{38}$ of follow-up.

\section{Depression}

The effects of PCC on depression were evaluated in three studies using the Cornell Scale for Depression in Dementia (CSDD) and the Geriatric Depression Scale (GDS); in both studies, a positive effect was observed. Meta-analysis of the effectiveness of PCC on the level of depression in dementia patients included three studies (Figure 5) in which pooled data showed that PCC significantly reduced the severity of depression (SMD: -0.242 ; 95\% CI: -0.390 to -0.093 ). However, there was no evidence for lasting effects of PCC intervention on depression.

\section{Discussion}

The findings of this systematic review of the literature and meta-analysis have shown that PCC in long-term and homebased care facilities significantly improved the QoL and reduced NPS in patients with dementia. This review included 19 published clinical trials with a total of 3,985 participants. Meta-analysis demonstrated that PCC for dementia could 
A

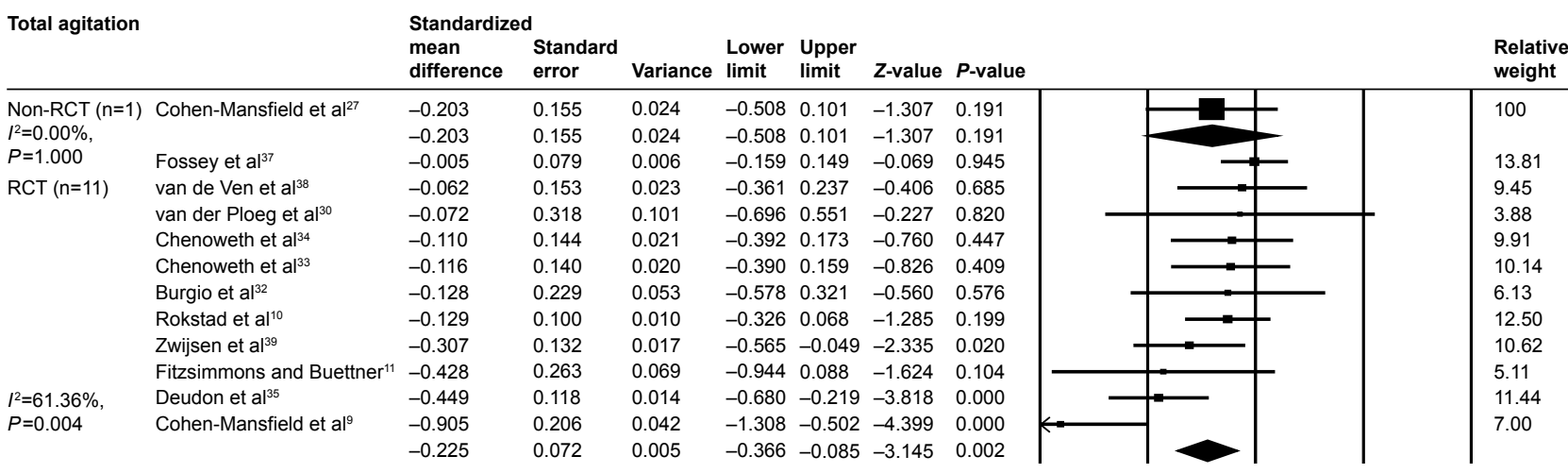

B

Agitation by duration

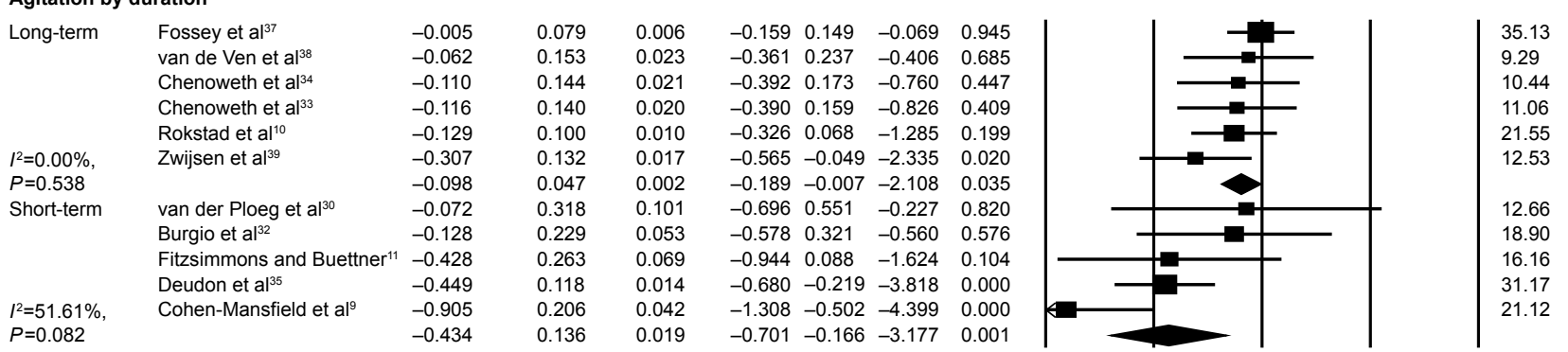

C

Agitation by intervention type

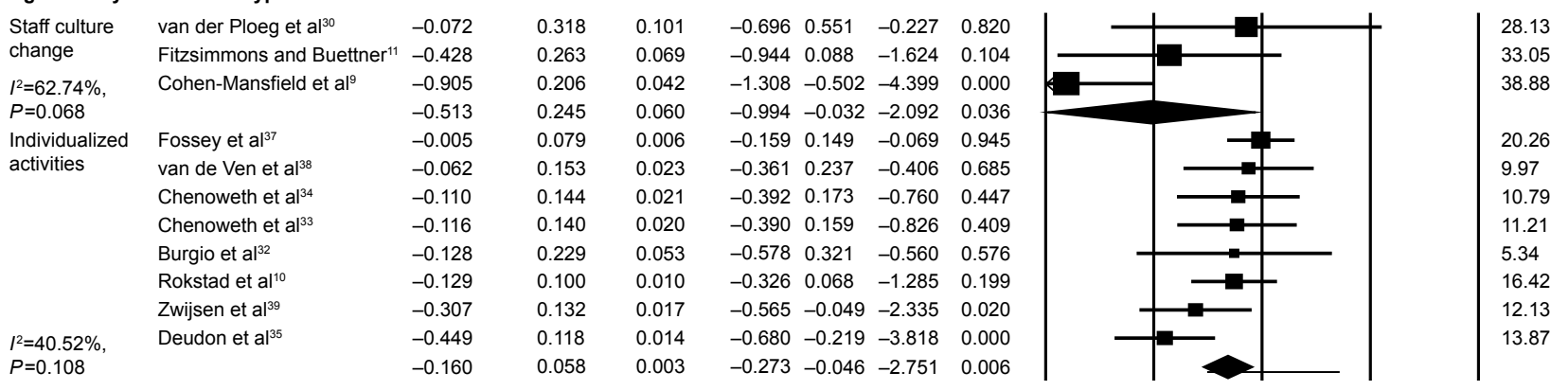

D

Agitation by severity

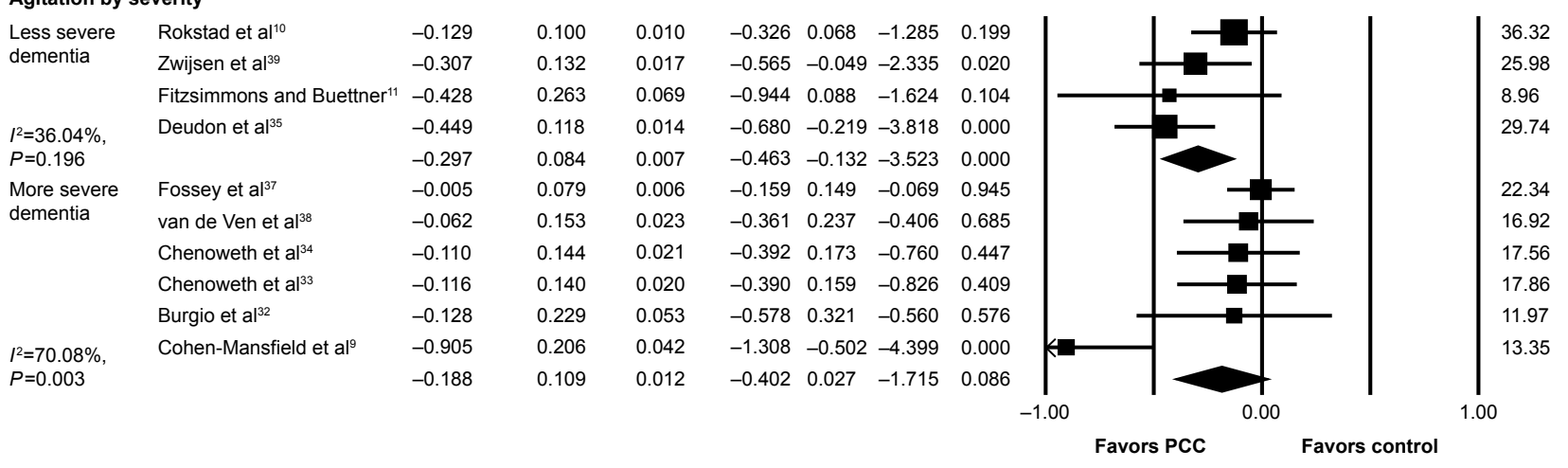

Figure 2 PCC intervention versus usual care, outcome: agitation.

Notes: (A) Total effect. (B) subgroup analysis by intervention duration. Short-term $=10$ days to 3 months, long-term $=>3$ months (C) Subgroup analysis by intervention type. (D) Subgroup analysis by dementia severity in the study participants. Severe dementia group $=$ mean MMSE $<10$ or majority population ( $>70 \%$ ) diagnosed with moderate to severe dementia vs less severe dementia group = mean MMSE $>10$ or severe dementia patients comprised $<30 \%$ of study participants.

Abbreviations: MMSE, mini mental state exam; PCC, person-centered care; RCT, randomized controlled trial. 


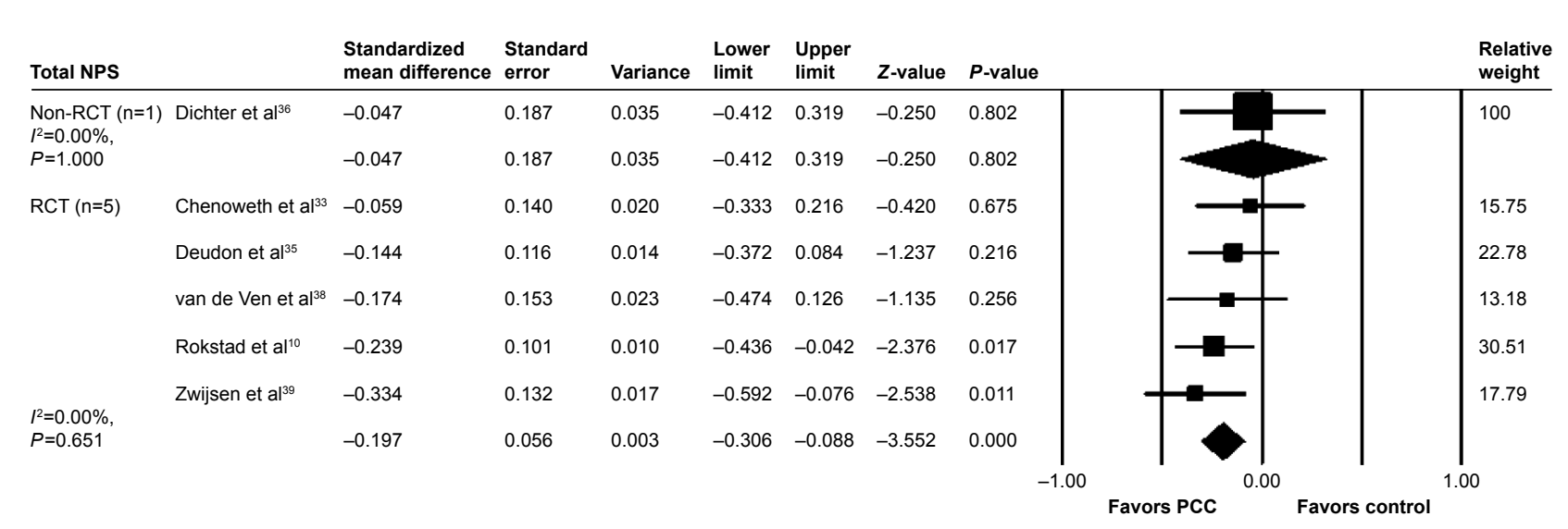

Figure 3 PCC intervention versus usual care, outcome: NPS.

Abbreviations: NPS, neuropsychiatric symptoms; PCC, person-centered care; RCT, randomized controlled trial.

reduce agitation, NPS, and depression and that PCC interventions could be used for long terms as alternatives to conventional dementia care. Although we did not restrict the settings for the studies analyzed, all PCC interventions were conducted in either long-term care settings or home care settings. This review included two studies that implemented PCC for individuals living at home, and no interventions were performed in the acute care setting. Therefore, there were insufficient data for the effects of PCC outside long-term care settings. Thus, we could provide sufficient evidence that PCC has the potential to optimize quality care for individuals with dementia in long-term care settings. The disease severity of study participants, the intervention duration, and type played significant roles, depending on the type of target outcome.

The meta-analysis confirmed the beneficial effect of PCC on reducing agitation in dementia. The findings of this study are supported by previous studies that have shown that people with dementia rarely exhibited agitation and other challenging behaviors when engaged in certain types of activities, ${ }^{40,41}$ including activities of personal interest. ${ }^{9,27}$ Therefore, it would seem logical that the benefits of therapy in dementia could be improved with the use of PCC approaches, which include personal preference and interests.

The finding of the effectiveness of PCC in reducing depression in individuals with dementia and improving the QoL but only with the long-term interventions is supported by a previous study that identified a positive effect of personal relationships, that develop in a long term (over at least 3 months) ${ }^{42}$ The PCC approach emphasizes that staff develop meaningful relationships with residents, which promote opportunities for social interactions. This relationshipbased care may be particularly important for individuals with dementia who are institutionalized for a long term, often until their death. ${ }^{15}$ Establishing such relationships demands time and effort. Therefore, PCC interventions could be planned for the long term to improve the QoL of individuals with dementia. The meta-analysis in this study also showed that PCC was more effective in improving QoL for individuals with less severe dementia. This finding may be because individuals who are at an early stage of dementia have a greater awareness of disease-related deficits and are more likely to feel depressed resulting in reduced QoL. ${ }^{43}$

Meta-analysis identified that PCC interventions working directly with dementia patients had beneficial effects, reducing agitation and NPS, but the effects were mostly for a short term and lasted 6 weeks on average. The greater benefits of short-term intervention may be linked to the increased engagement between the health care provider and the patient and the intensity of the care program. However, none of these activity-based interventions followed up the assessments, and so it is unclear whether the effects of these short-term interventions relied on an external resource that could last and for how long. Researchers and clinicians cannot assume that they will see the same effects in clinical practice as they see in more controlled interventions that rely on external resources. The findings of this study showed smaller and statistically nonsignificant effects of long-term interventions on agitation. Because most long-term interventions were implemented in the long-term care setting using educational strategies for internal care staff, this variation may be caused by varied staff motivation and skills for implementing PCC. Most of the studies with long-term and staff education interventions lacked detail on how to carry out PCC, who carried it out, and to what extent, and lacked details 


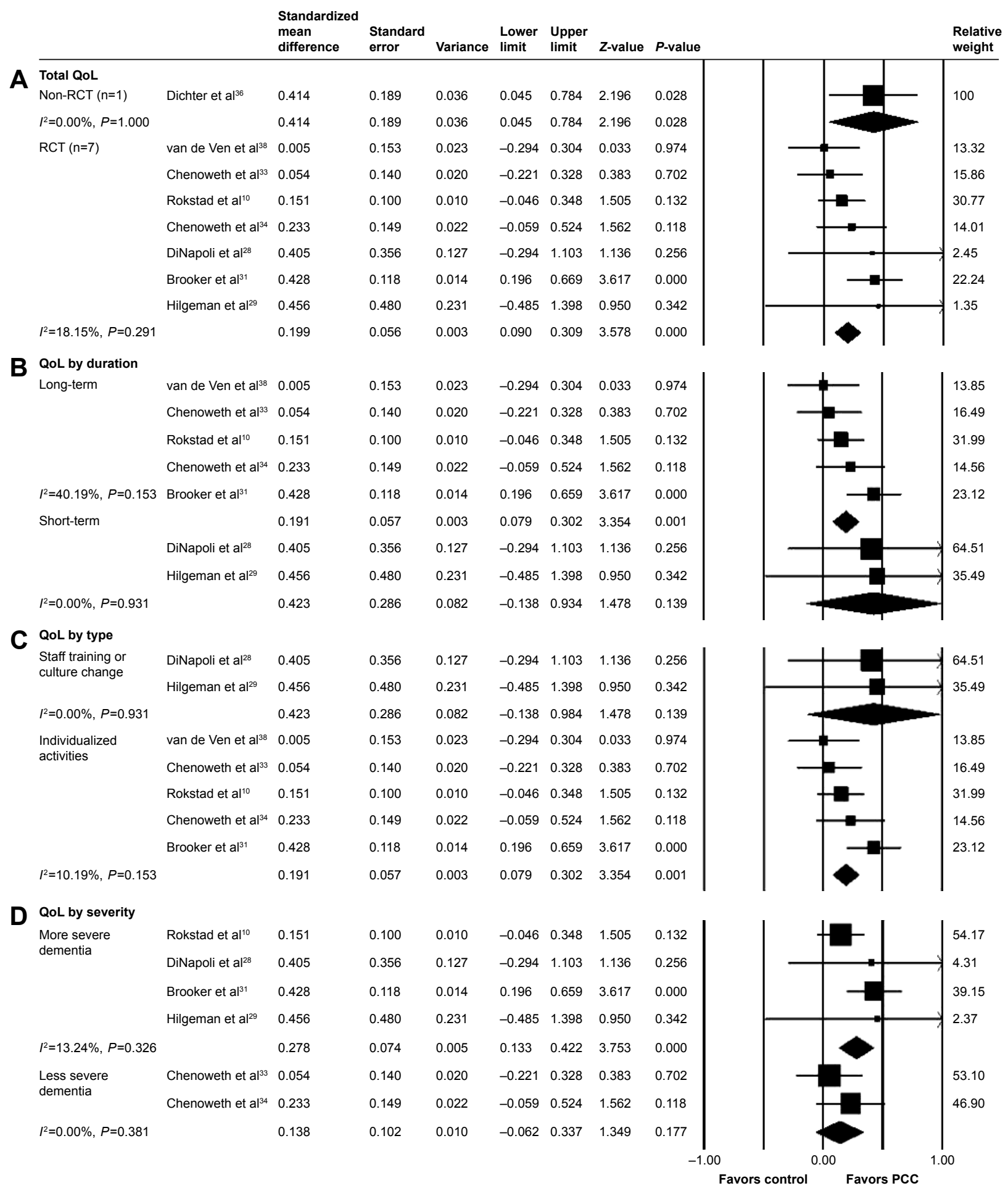

Figure 4 PCC intervention versus usual care, outcome: QoL.

Notes: (A) Total effect. (B) subgroup analysis by intervention duration. Short-term $=10$ days to 3 months, long-term =>3 months. (C) Subgroup analysis by intervention type. (D) Subgroup analysis by dementia severity in the study participants. Severe dementia group $=$ mean MMSE $<10$ or majority population ( $>70 \%)$ diagnosed with moderate to severe dementia vs less severe dementia group. Mean MMSE $>10$ or severe dementia patients comprised $<30 \%$ of study participants.

Abbreviations: MMSE, mini mental state exam; PCC, person-centered care; QoL, quality of life; RCT, randomized controlled trial.

of whether manuals were used and how the studies measured the extent and degree of staff engagement. One study identified that there were barriers to PCC interventions, including staff shortages and lack of knowledge and education regarding PCC. ${ }^{44}$ Staff training and the implementation of PCC for daily practice are time-consuming and require considerable dedication and a clear understanding of benefits of PCC with clear guidelines.

The advantages of PCC, however, outweigh the difficulties experienced by staff members, with a positive influence 


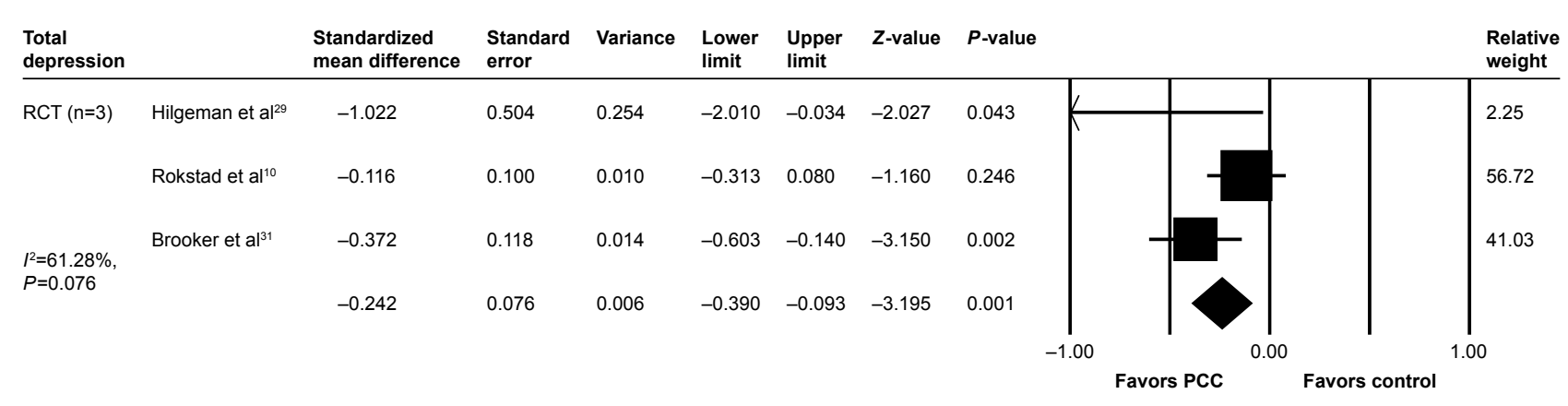

Figure 5 PCC intervention versus usual care, outcome: depression.

Abbreviations: PCC, person-centered care; RCTs, randomized controlled trials.

on stress reduction, reduced burnout, and increased job satisfaction. ${ }^{5,15,44}$ PCC enables staff to respond more effectively because they are better prepared for challenging situations that arise during the care of individuals who have dementia. Most importantly, PCC is reported to be the preferred type of care that staff would wish to provide. 5 Thus, along with continuous training and education, we recommend strategies that motivate and encourage staff to carry out PCC in clinical practice that may achieve sustained or better effects over time. A previous study reported the implementation of PCC interventions and placed considerable emphasis on the importance of influencing and changing the leaders and institutional culture toward PCC, which led to frontline staff implementing PCC in their daily practice. ${ }^{44}$

Two studies used PCC for individuals with dementia living at home, but data could not be pooled as different outcomes were measured. ${ }^{11,29}$ Although conclusions about the effectiveness of PCC within this population with dementia could not be made there may be the potential for the effective application of PCC with dementia patients who reside in the community where care is often given by informal caregivers, who are mainly family members. In support of recent studies on ways to alleviate stress in informal caregivers ${ }^{45}$ the introduction of the essential elements of PCC may reduce the likelihood of institutionalization for the patient and also reduce stress for the caregiver.

\section{Limitations}

This study had several limitations. This review included two studies of PCC for individuals living at home, but there were no studies of PCC intervention performed in the acute care setting. In some studies, more than one measurement was used to assess the same outcome, which led to difficulties in choosing one measurement over another as the more appropriate and relevant measure for inclusion in a meta-analysis. Moreover, nonpharmacological interventions are more likely to be affected by the context of the study, such as the type of health care setting, and by cultural factors. It was not possible to examine specific attributes that could have an impact on the effectiveness of interventions in detail from the review, such as institutional organizational factors, staffing levels, and health care managerial systems, all of which have an effect on the effectiveness of the PCC intervention program. A further limitation was that internal care staff levels of care, including the degree of staff engagement when implementing PCC, were not measured. Possible discrepancies in the levels of staff engagement may explain the variations in outcomes among included studies that used the same PCC intervention in a similar population. Also, this review did not investigate the impact of the use of medication on the outcome of PCC, which would be an important area for future studies on the effectiveness of PCC as a nonpharmacological approach to dementia care.

The findings of this review may have some implications for future clinical practice. Depending on actual applicability and feasibility, intervention design should be varied. Intensive and activity-based PCC intervention can reduce behavioral issues effectively within the short term. Shortterm interventions, with more frequent exposure to PCC activities, ensured a higher engagement of people with dementia in PCC-based programs, producing better outcomes for reducing agitation. However, for the emotional outcomes, depression, and QoL, long-term and interactive interventions should be used. PCC interventions aimed at improving the QoL of individuals with dementia should take place over time and be designed to promote the active involvement of the internal care staff. PCC interventions can be considered especially for individuals who have a diagnosis of early-stage dementia. In particular, for QoL and depression, PCC interventions targeting people at the early stage of disease may prevent further deterioration caused by depression, leading to improved QoL in individuals with dementia.

Considering the ease of application of the PCC program, the use of external resources would be desirable and may 
produce more immediate effects on reducing problematic behavior when adopting person-centeredness for dementia in the care setting. However, durability and sustained effect of these interventions may not be guaranteed, as there have been no studies to evaluate the lasting effectiveness of PCC. Because dementia is a chronic disease, maintenance of therapy may be an important component for the implementation of a successful intervention and should be evaluated further. ${ }^{46}$ Recent studies have shown a substantial benefit for staff training in PCC for up to 12 months. ${ }^{33-35}$ Furthermore, PCC interventions can improve QoL which is the ultimate goal for dementia care as there is no cure for the disease ${ }^{46}$ Therefore, PCC interventions should be based on agreed guidelines and manuals of care and should focus on staff education and training to implement PCC for a long term. The effectiveness of PCC could be improved with time as staff awareness of the importance of PCC increases.

The findings of this review have implications for future research on the role of PCC to improve the QoL and reduce NPS in patients with dementia. This review has shown that measures to assess the how well staff implement PCC should be incorporated into future studies, with attention given to the consistency of PCC in daily practice. PCC interventions required extensive staff training and education. This review has indicated the need for clear guidelines and the use of standardized staff manuals on PCC practice. This systematic review did not find sufficient high-quality evidence to state that any particular intervention was clearly effective. Therefore, further more robust studies are recommended. Future research utilizing precise methods for randomization, allocation concealment, and blinding of those who collect the data can confirm the validity of the findings from this review and meta-analysis. Also, the effects of PCC on family caregivers should be studied to provide comprehensive viewpoints concerning dementia care. More studies with rigorous designs are needed to determine the effectiveness of PCC on cognitive disease-related symptoms as well as QoL of individuals with dementia.

\section{Conclusion}

Systematic literature review and meta-analysis showed that intensive PCC for people with dementia significantly improved NPS and QoL when compared with usual care. The findings support the role of education and skills training for care staff to enhance QoL and to sustain the beneficial effects of PCC for patients with dementia and NPS.

\section{Acknowledgments}

The authors would like to thank Dr Nancy Moore, editor of the Arizona State University College of Nursing and Health Innovation, for reviewing drafts of this manuscript. This study was supported by the Basic Science Research Program through the National Research Foundation of Korea (NRF) funded by the Ministry of Science, ICT and Future Planning (NRF-2013R1A2A2A01069090).

\section{Disclosure}

The authors report no conflicts of interest in this work.

\section{References}

1. Alzheimer's Disease International. Dementia: A Public Health Priority. Geneva, Switzerland: World Health Organization; 2015.

2. Ballard C, Corbett A. Management of neuropsychiatric symptoms in people with dementia. CNS Drugs. 2010;24(9):729-739.

3. Kitwood T, Bredin K. Towards a theory of dementia care: personhood and well-being. Ageing Soc. 1992;12:269-287.

4. Schölzel-Dorenbos CJ, Meeuwsen EJ, Olde Rikkert MG. Integrating unmet needs into dementia health-related quality of life research and care: introduction of the hierarchy model of needs in dementia. Aging Ment Health. 2010;14(1):113-119.

5. Edvardsson D, Fetherstonhaugh D, McAuliffe L, Nay R, Chenco C. Job satisfaction amongst aged care staff: exploring the influence of person-centered care provision. Int Psychogeriatr. 2011;23(8): 1205-1212.

6. Brooker D. What is person-centred care in dementia? Rev Clin Gerontol. 2003;13(3):215-222.

7. Edvardsson D, Fetherstonhaugh D, Nay R. Promoting a continuation of self and normality: person-centred care as described by people with dementia, their family members and aged care staff. J Clin Nurs. 2010;19(17-18):2611-2618.

8. Brooker D. Dementia care mapping: a review of the research literature. Gerontologist. 2005;45(1):11-18.

9. Cohen-Mansfield J, Thein K, Marx MS, Dakheel-Ali M, Freedman L. Efficacy of nonpharmacologic interventions for agitation in advanced dementia: a randomized, placebo-controlled trial. J Clin Psychiatry. 2012;73(9):1255-1261.

10. Rokstad AM, Røsvik J, Kirkevold Ø, Selbaek G, Saltyte Benth J, Engedal K. The effect of person-centered dementia care to prevent agitation and other neuropsychiatric symptoms and enhance quality of life in nursing home patients: a 10-month randomized controlled trial. Dement Geriatr Cogn Disord. 2013;36(5-6):340-353.

11. Fitzsimmons S, Buettner LL. Therapeutic recreation interventions for need-driven dementia-compromised. Am J Alzheimers Dis Other Demen. 2002;17(6):367-381.

12. Brooker D. Person-Centred Dementia Care: Making Services Better. London, UK: Jessica Kingsley Publishers; 2006.

13. Cognitive Decline Partnership Centre. Clinical Practice Guidelines for Dementia in Australia. Sydney, Australia: Cognitive Decline Partnership Centre; 2015.

14. UK Department of Health. Living Well with Dementia: A National Dementia Strategy. London, UK: Department of Health; 2009.

15. Li J, Porock D. Resident outcomes of person-centered care in long-term care: a narrative review of interventional research. Int J Nurs Stud. 2014; 51(10):1395-1415.

16. Barbosa A, Sousa L, Nolan M, Figueiredo D. Effects of person-centered care approaches to dementia care on staff: a systematic review. Am J Alzheimers Dis Other Demen. 2015;30(8):713-722. 
17. Fossey J, Masson S, Stafford J, Lawrence V, Corbett A, Ballard C. The disconnect between evidence and practice: a systematic review of personcentred interventions and training manuals for care home staff working with people with dementia. Int J Geriatr Psychiatry. 2014;29(8):797-807.

18. Love K, Pinkowitz J. Person-centered care for people with dementia: a theoretical and conceptual framework. Generations. 2013;37(3): 23-29.

19. Moher D, Liberati A, Tetzlaff J, Altman DG; PRISMA Group. Preferred reporting items for systematic reviews and meta-analyses: the PRISMA statement. Ann Intern Med. 2009;151(4):264-269, W64.

20. Higgins JP. Cochrane Handbook for Systematic Reviews of Interventions. Chichester, UK: Wiley-Blackwell; 2011.

21. RevMan. Review Manager (RevMan) [Computer program]. Version 5.1. Copenhagen, Europe: The Nordic Cochrane Centre, The Cochrane Collaboration; 2011.

22. Kim SY, Park JE, Lee YJ, et al. Testing a tool for assessing the risk of bias for nonrandomized studies showed moderate reliability and promising validity. J Clin Epidemiol. 2013;66(4):408-414.

23. Borenstein M, Hedges L, Higgins J, Rothstein H. Comprehensive Metaanalysis Version 3 [Computer software]. Englewood, NJ: Biostat; 2015.

24. Buettner L, Ferrario J. Therapeutic recreation-nursing team: a therapeutic intervention for nursing home residents with dementia. Annu Ther Recreation. 1998;7:21-28.

25. Buettner LL. Simple pleasures: a multilevel sensorimotor intervention for nursing home residents with dementia. Am J Alzheimers Dis Other Demen. 1999;14(1):41-52.

26. Burack OR, Weiner AS, Reinhardt JP. The impact of culture change on elders' behavioral symptoms: a longitudinal study. J Am Med Dir Assoc. 2012;13(6):522-528.

27. Cohen-Mansfield J, Libin A, Marx MS. Nonpharmacological treatment of agitation: a controlled trial of systematic individualized intervention. J Gerontol A Biol Sci Med Sci. 2007;62(8):908-916.

28. DiNapoli EA, Scogin F, Bryant AN, Sebastian S, Mundy MJ. Effect of individualized social activities on quality of life among older adults with mild to moderate cognitive impairment in a geriatric psychiatry facility. Aging Ment Health. 2016;20(3):262-270.

29. Hilgeman MM, Allen RS, Snow AL, Durkin DW, DeCoster J, Burgio LD. Preserving identity and planning for advance care (PIPAC): preliminary outcomes from a patient-centered intervention for individuals with mild dementia. Aging Ment Health. 2014;18(4):411-424.

30. van der Ploeg ES, Eppingstall B, Camp CJ, Runci SJ, Taffe J, O'Connor DW. A randomized crossover trial to study the effect of personalized, one-to-one interaction using Montessori-based activities on agitation, affect, and engagement in nursing home residents with dementia. Int Psychogeriatr. 2013;25(4):565-575.

31. Brooker DJ, Argyle E, Scally AJ, Clancy D. The enriched opportunities programme for people with dementia: a cluster-randomised controlled trial in 10 extra care housing schemes. Aging Ment Health. 2011;15(8): 1008-1017.

32. Burgio LD, Stevens A, Burgio KL, Roth DL, Paul P, Gerstle J. Teaching and maintaining behavior management skills in the nursing home. Gerontologist. 2002;42(4):487-496
33. Chenoweth L, King MT, Jeon YH, et al. Caring for aged dementia care resident study (CADRES) of person-centred care, dementia-care mapping, and usual care in dementia: a cluster randomised trial. Lancet Neurol. 2009;8(4):317-325.

34. Chenoweth L, Forbes I, Fleming R, et al. PerCEN: a cluster randomized controlled trial of person-centered residential care and environment for people with dementia. Int Psychogeriatr. 2014;20(7): $1147-1160$

35. Deudon A, Maubourguet N, Gervais X, et al. Non-pharmacological management of behavioural symptoms in nursing homes. Int J Geriatr Psychiatry. 2009;24(12):1386-1395.

36. Dichter MN, Quasdorf T, Schwab CG, et al. Dementia care mapping: effects on residents' quality of life and challenging behavior in German nursing homes: a quasi-experimental trial. Int Psychogeriatr. 2015; 27(11):1875-1892.

37. Fossey J, Ballard C, Juszczak E, et al. Effect of enhanced psychosocial care on antipsychotic use in nursing home residents with severe dementia: cluster randomised trial. BMJ. 2006;332(7544):756-761.

38. van de Ven G, Draskovic I, Adang EM, et al. Effects of dementia-care mapping on residents and staff of care homes: a pragmatic clusterrandomised controlled trial. PLoS One. 2013;8(7):e67325.

39. Zwijsen SA, Smalbrugge M, Eefsting JA, et al. Coming to grips with challenging behavior: a cluster-randomized controlled trial on the effects of a multidisciplinary care program for challenging behavior in dementia. J Am Med Dir Assoc. 2014;15(7):531.e1-531.e10.

40. Oppikofer S, Geschwindner H. Nursing interventions in cases of agitation and dementia. Dementia (London). 2014;13(3):306-317.

41. Janzen S, Zecevic AA, Kloseck M, Orange JB. Managing agitation using nonpharmacological interventions for seniors with dementia. Am J Alzheimers Dis Other Demen. 2013;28(5):524-532.

42. Spector A, Orrell M. Quality of life (QoL) in dementia: a comparison of the perceptions of people with dementia and care staff in residential homes. Alzheimer Dis Assoc Disord. 2006;20(3):160-165.

43. Beerens HC, Sutcliffe C, Renom-Guiteras A, et al. Quality of life and quality of care for people with dementia receiving long term institutional care or professional home care: the European right time place care study. J Am Med Dir Assoc. 2014;15(1):54-61.

44. Jeon YH, Simpson JM, Li Z, et al. Cluster randomized controlled trial of an aged care specific leadership and management program to improve work environment, staff turnover, and care quality. J Am Med Dir Assoc. 2015; 16(7):619-629.

45. Gauthier S, Cummings J, Ballard C, et al. Management of behavioral problems in Alzheimer's disease. Int Psychogeriatr. 2010;22(3): 346-372.

46. Kaasalainen S, Williams J, Hadjustavropoulos T, et al. Creating bridges between researchers and long-term care homes to promote quality of life. Qual Health Res. 2010;20(12):1689-1704.
Clinical Interventions in Aging

\section{Publish your work in this journal}

Clinical Interventions in Aging is an international, peer-reviewed journal focusing on evidence-based reports on the value or lack thereof of treatments intended to prevent or delay the onset of maladaptive correlates of aging in human beings. This journal is indexed on PubMed Central, MedLine,

\section{Dovepress}

CAS, Scopus and the Elsevier Bibliographic databases. The manuscript management system is completely online and includes a very quick and fair peer-review system, which is all easy to use. Visit http://www.dovepress. com/testimonials.php to read real quotes from published authors. 